Revista Brasil. Bot., V.32, n.4, p.793-803, out.-dez. 2009

\title{
Viabilidade e vigor de sementes de Caesalpinia echinata Lam. (pau-brasil - Leguminosae) pelo teste de tetrazólio ${ }^{1}$
}

\author{
EDMIR VICENTE LAMARCA², SIMONE NADUR MOTA LEDUC ${ }^{2}$ e \\ CLAUDIO JOSÉ BARBEDO ${ }^{3,4}$
}

(recebido: 23 de outubro de 2008; aceito: 16 de setembro de 2009)

\begin{abstract}
Viability and vigor of seeds of Caesalpinia echinata Lam. (brazilwood - Leguminosae) by tetrazolium test). As an important method to quickly evaluate seed vigor and deterioration, both of them related to seed physiological quality, the tetrazolium test was analyzed for seeds of Caesalpinia echinata Lam. (brazilwood). Mature seeds were incubated in 0.05\% to $1.00 \%$ tetrazolium solutions for a period varying from 1 to 24 hours, at $35{ }^{\circ} \mathrm{C}$ without light. Then, embryos of different levels of deterioration were analyzed under the best conditions ( $0.05 \%-0.075 \%$ for 2 hours) of incubation. It was possible to identify eight levels of vigor which will be important to a brazilwood seed lot diagnosis in a short time (4 hours) and to identify different types of embryo damages, the later essential to estimate seed storability.
\end{abstract}

Key words - analysis, germination, physiological quality, respiration, vigor test

RESUMO - (Viabilidade e vigor de sementes de Caesalpinia echinata Lam. (pau-brasil - Leguminosae) pelo teste de tetrazólio). O teste de tetrazólio é importante componente para a avaliação da qualidade fisiológica de sementes, possibilitando fornecer rápida avaliação do vigor e do estado de deterioração. Objetivou-se desenvolver metodologia do teste de tetrazólio para sementes de Caesalpinia echinata Lam. (pau-brasil). Sementes colhidas por ocasião de sua maturidade fisiológica foram incubadas, com ou sem tegumento, em soluções de tetrazólio em concentrações que variaram de 0,05\% a 1,00\%, por períodos que variaram de 1 a 24 horas, a $35^{\circ} \mathrm{C}$ na ausência de luz. As melhores combinações entre concentração e período de incubação (0,05\% a $0,075 \%$ por 2 horas) foram aplicadas a amostras de sementes, sem tegumento, com diferentes níveis de deterioração. Os resultados permitiram estabelecer oito classes de vigor, que permitirão diagnosticar a qualidade de lotes de sementes de paubrasil em 4 horas, bem como identificar uma série de injúrias nos embriões, fundamentais para previsão de armazenabilidade das sementes.

Palavras-chave - análise, germinação, qualidade fisiológica, respiração, teste de vigor

\section{Introdução}

O pau-brasil (Caesalpinia echinata Lam.), ou ibirapitanga, pertencente à família Leguminosae Caesalpinioideae, é espécie nativa do Brasil, de ocorrência natural desde o Rio Grande do Norte até o Rio de Janeiro, na floresta pluvial atlântica. Atualmente, vem sendo utilizado na arborização urbana (Rocha \& Barbedo 2008) e na fabricação de arcos de instrumentos musicais com corda (Rocha 2004). Embora outras madeiras estejam sendo empregadas no comércio nacional para a produção de arcos, a madeira de pau-brasil, mundialmente utilizada nessas confecções, apresenta características únicas de ressonância, densidade e durabilidade (Angyalossy et al. 2005).

1. Parte da dissertação de mestrado do primeiro autor, Programa de Pós-Graduação em Biodiversidade Vegetal e Meio Ambiente, Instituto de Botânica.

2. Instituto de Botânica, Programa de Pós-Graduação em Biodiversidade Vegetal e Meio Ambiente, Av. Miguel Stéfano 3687, 04301-012 São Paulo, SP, Brasil.

3. Instituto de Botânica, Seção de Sementes e Melhoramento Vegetal.

4. Autor para correspondência: claudio.barbedo@pesquisador.cnpq.br
A despeito de sua atual raridade natural, há diversas iniciativas, públicas e privadas, para a preservação ex situ do pau-brasil, principalmente no Estado de São Paulo (Rocha 2004). Para que essa preservação seja eficiente, a produção e armazenamento de suas sementes assume papel fundamental e, nesse caso, há necessidade de monitoramento da deterioração dessas sementes ao longo do armazenamento. Essa deterioração, mais rápida quanto mais hidratadas estiverem as sementes (Villela \& Peres 2004), ocorre mesmo nas sementes ortodoxas com baixo teor de água. As sementes de pau-brasil, por exemplo, apresentam comportamento ortodoxo, tolerando redução do teor de água até 7\% (Barbedo et al. 2002) e, em temperaturas de congelamento $\left(-5\right.$ a $\left.-18{ }^{\circ} \mathrm{C}\right)$, podem ser armazenadas por até 24 meses (Hellmann et al. 2006). Contudo, quando em temperatura ambiente, mesmo com esse baixo teor de água não ultrapassam três meses de armazenamento (Barbedo et al. 2002).

A qualidade das sementes é máxima por ocasião da maturidade fisiológica; a partir desse momento, as sementes começam a se deteriorar até perderem sua capacidade de germinar. A duração deste processo é determinada principalmente pela interação entre herança 
genética, grau de hidratação e temperatura (Delouche 2002). A deterioração proporciona alterações fisiológicas, bioquímicas, físicas e citológicas, determinando a queda do vigor, culminando com a morte da semente (Marcos Filho 2005).

A detecção da deterioração de sementes por intermédio de testes de vigor pode ser entendida como componente importante na avaliação da qualidade fisiológica, possibilitando avaliação rápida do vigor, auxiliando na tomada de decisões quanto ao uso ou descarte de lotes de sementes (McDonald 1999).

O principal desafio das pesquisas sobre testes de vigor está na identificação de parâmetros relacionados à deterioração das sementes que precedem a perda da capacidade germinativa. Dessa forma, torna-se importante o uso de testes que possibilitem a detecção dos estágios iniciais da deterioração, relacionados ao sistema de membranas, atividade enzimática e redução dos mecanismos energéticos. Dentro deste contexto, destaca-se o teste de tetrazólio.

O teste de tetrazólio é um método rápido para estimar a viabilidade e o vigor de sementes; baseia-se na atividade das enzimas desidrogenases que reduzem o cloreto 2,3,5 trifenil tetrazólio nos tecidos vivos da semente, onde íons de hidrogênio são transferidos para o referido composto (Delouche et al. 1976). Quando as sementes são imersas na solução de tetrazólio, esta se difunde através dos tecidos ocorrendo, nas células vivas, a reação de redução, resultando na formação de um composto vermelho, não difusível, conhecido como trifenilformazan, indicando haver atividade respiratória e, conseqüentemente, que o tecido é viável. Tecidos inviáveis não reagem com a solução, permanecendo na sua cor natural e tecidos em deterioração apresentam coloração vermelho-intenso (Delouche et al. 1976, França Neto 1994).

Sementes de diversas espécies cultivadas já foram amplamente pesquisadas, tendo-se metodologia definida e padronizada para a realização do teste de tetrazólio. Em relação às espécies nativas do Brasil, principalmente as arbóreas, poucas foram estudadas e, mesmo nessas, não é possível padronizar a metodologia para a execução desse teste, cada espécie necessitando processos próprios. Assim, dos trabalhos descritos na literatura pode-se verificar variações na melhor concentração do sal de tetrazólio, desde 0,05\%, para Parapiptadenia rigida (Benth.) Brenan (Fogaça 2003) e Schizolobium parahyba (Vell.) Blake (Ferreira et al. 2007) até 0,5\%, para Tabebuia serratifolia (Vahl) Nich. (Oliveira et al. 2005). Tal variação é notada, também, no tempo de incubação na solução de tetrazólio, desde 60 minutos, para Astronium graveolens Jacq. (Fogaça 2003), até 6 horas, para Pterodon pubescens Benth. (Ferreira et al. 2001), encontrando-se referências de incubação por até 48 horas (Oliveira et al. 2005).

Diante do exposto, o presente trabalho teve como objetivo desenvolver metodologia para utilização do teste de tetrazólio em sementes de pau-brasil. Para tanto, inicialmente procurou-se estabelecer o tempo de embebição necessário à ativação de enzimas da respiração; em seguida, procurou-se determinar a eficiência do teste de tetrazólio em sementes inteiras, variando-se tempo de incubação e concentração da solução de tetrazólio; posteriormente, procurou-se determinar a eficiência do teste de tetrazólio em embriões (sem tegumento); finalmente, com os resultados dos experimentos anteriores, procurou-se estabelecer classes de viabilidade e de vigor para as sementes.

\section{Material e métodos}

Material vegetal - As sementes foram obtidas de frutos maduros (Borges et al. 2005) colhidos em abril de 2005 na Estação Ecológica de Tapacurá, em São Lourenço da Mata, PE (759' S, 3502' W) e em dezembro de 2005 e de 2006 na Reserva Biológica e Estação Experimental de Mogi

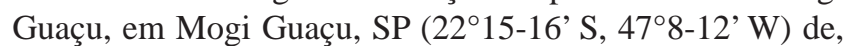
aproximadamente, 15 a 20 matrizes. Os frutos foram mantidos ao sol, sobre base de alvenaria, cobertos por sombrite, para abertura espontânea. À medida que as sementes foram liberadas dos frutos, foram armazenadas em câmara fria a $7^{\circ} \mathrm{C}$ até o início dos experimentos (Bilia et al. 1998, Barbedo et al. 2002), não excedendo 14 dias.

Determinações físicas e fisiológicas - As sementes foram caracterizadas, inicialmente, quanto ao teor de água, potencial hídrico (embriões) e germinação. O teor de água foi determinado gravimetricamente, em estufa a $103^{\circ} \mathrm{C}$ por 17 horas (ISTA 1985), sendo os resultados apresentados em base úmida (Brasil 1992). O potencial hídrico foi medido, em embriões sem tegumento, por meio de potenciômetro WP4 (Decagon), basendo-se na temperatura do ponto de orvalho do ar em equilíbrio com a amostra examinada. A aferição do potencial foi realizada por meio de isotermas de sorção de água em soluções de polietileno glicol 6.000.

$\mathrm{O}$ teste de germinação foi conduzido em germinadores MA400 (Marconi), com 100\% de umidade relativa do ar e regulados para a temperatura constante de $25^{\circ} \mathrm{C}$, com luz contínua (Mello \& Barbedo 2007). O teste foi conduzido em rolo de papel germitest, com duas folhas para base e uma para cobertura (Brasil 1992). As avaliações de germinação foram realizadas diariamente, durante 15 dias, sendo registradas as sementes que emitiram raiz primária (para o cálculo da germinação) e as que apresentaram capacidade de produção de plântulas normais (para o cálculo do desenvolvimento de 
plântulas normais). Foi calculado, ainda, o vigor das sementes pelo índice de velocidade de germinação (IVG), conforme Maguire (1962).

Obtenção da curva de hidratação das sementes - Visando a identificar o final da fase I e início da fase II da germinação, descritas por Bewley \& Black (1994), sementes originárias de Mogi Guaçu, colhidas em 2005, foram submetidas a secagem em estufa com circulação forçada de ar, a $40^{\circ} \mathrm{C}$ (Barbedo et al. 2002), até apresentarem $7 \%$ de água e armazenadas por 5 meses a $8 \pm 2{ }^{\circ} \mathrm{C}$. A seguir, foram colocadas para embeber a $25{ }^{\circ} \mathrm{C}$ (Mello \& Barbedo 2007), em folha de papel previamente umedecido com água pura (2,5 vezes o peso do papel seco) e, a cada 5 minutos, até os primeiros 60 minutos, ou a cada 30 minutos, a partir de 60 minutos, amostras foram retiradas para avaliação do teor de água e do potencial hídrico.

Com os resultados obtidos procurou-se selecionar os períodos correspondentes ao início dos processos metabólicos e respiratórios e, conseqüentemente, o inicio da atividade das enzimas desidrogenases.

Concentração do sal de tetrazólio e período de exposição de sementes inteiras - Diferentes concentrações do sal cloreto 2,3,5 trifenil tetrazólio foram avaliadas, variando-se desde 0,250\% até 1,000\%. Em cada concentração, sementes de Mogi Guaçu foram incubadas pelos períodos de 2, 4, 12 e 24 horas, na temperatura de $35^{\circ} \mathrm{C}$, com ausência de luz. As sementes foram mantidas com seu tegumento, que apresentava trincas.

Ao final da incubação, as sementes foram lavadas em água corrente, seccionadas longitudinalmente e avaliadas individualmente, observando-se a presença e a localização de danos no eixo embrionário e nos cotilédones, principalmente nas áreas vitais do embrião (figura 1). Para efeito de classificação das áreas dos cotilédones, considerou-se a região mais próxima à região de inserção destes com o eixo embrionário como região proximal (figura 1 g) e a mais distante a esta inserção (incluindo-se toda a extremidade dos cotilédones), como região distal (figura 1 h). A diferenciação de cores dos tecidos obedeceu aos critérios estabelecidos por Delouche et al. (1976), Moore (1985) e França Neto (1994), ou seja, rosa suave representando tecido saudável, vermelho intenso para tecido em deterioração, ou seja, com respiração intensa e, ainda, cor natural do tecido para tecido morto.

Comparação da germinabilidade de sementes inteiras pelo teste de germinação e pelo tetrazólio - Sementes oriundas de São Lourenço da Mata, com ou sem prévia secagem, foram armazenadas sob duas temperaturas $\left(25^{\circ} \mathrm{C}\right.$ e $\left.-18^{\circ} \mathrm{C}\right)$ e duas diferentes embalagens (sacos de papel Kraft e frascos de vidro com tampa hermética). Destas combinações, após 1 ano de armazenamento foram selecionadas sementes com três qualidades fisiológicas distintas. Estas sementes foram submetidas simultaneamente ao teste de germinação e ao teste de tetrazólio. O teste de germinação foi conduzido segundo descrição acima e o do tetrazólio, baseando-se nos melhores resultados obtidos do experimento anterior, utilizou concentração de 0,250\% e 2 horas de incubação a $35^{\circ} \mathrm{C}$, na ausência de luz.

Concentração do sal de tetrazólio e período de exposição de embriões (sem tegumento) - Para avaliação da eficiência do teste de tetrazólio em embriões sem tegumento, três diferentes concentrações do sal, 0,075\%, 0,125\% e 0,250\%, foram avaliadas em sementes oriundas de Mogi Guaçu em 2006, sem armazenamento, variando-se o período de incubação desde 1 até 8 horas, nas temperaturas de 25, 30 e $35^{\circ} \mathrm{C}$, com ausência de luz. Ao final da incubação, seguiram-se os mesmos procedimentos descritos acima.

Obtenção de sementes com diferentes graus de deterioração - Para este experimento, foram coletados frutos diretamente das árvores, em Mogi Guaçu, em 2006, ao final da maturação das sementes (Borges et al. 2005). A extração destas foi feita manualmente sendo, então, submetidas ao envelhecimento acelerado, com o intuito de se obterem sementes com diferentes níveis de deterioração. Para tanto, as sementes foram expostas à temperatura constante de $42{ }^{\circ} \mathrm{C}$, dentro de caixas plásticas tipo gerbox, sobre tela de aço inox e $40 \mathrm{~mL}$

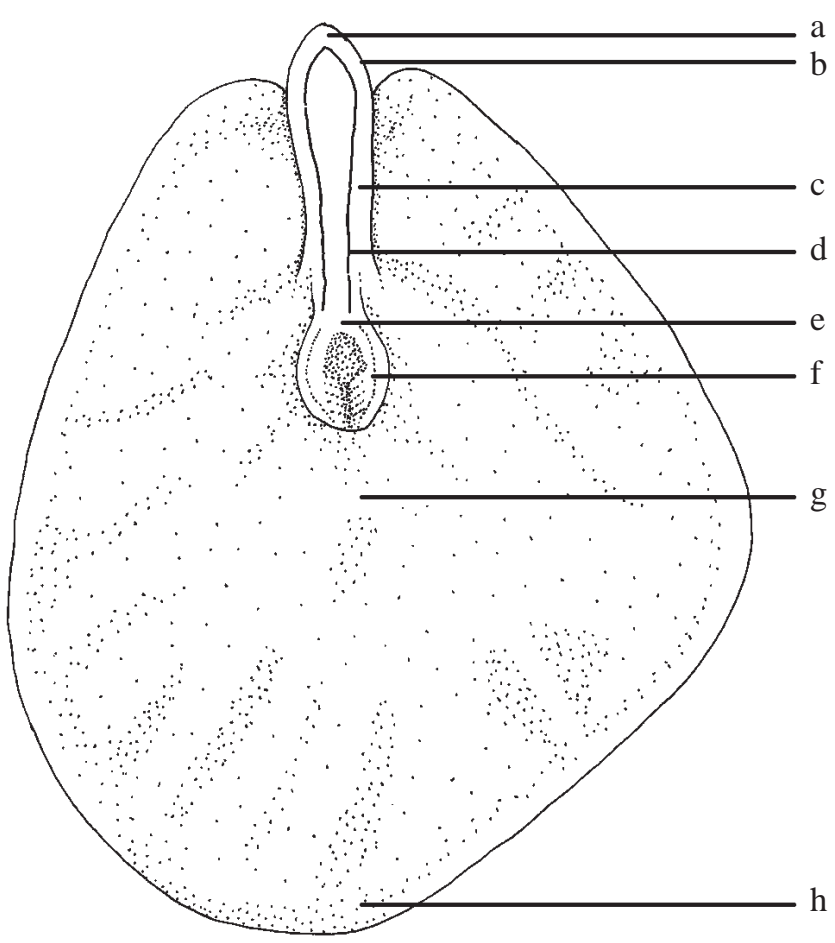

Figura 1. Secção longitudinal do embrião de pau-brasil. a-d. Eixo hipocótilo-radicular: radícula (a); protoderme (b); meristema fundamental (c) e procâmbio (d); região de inserção dos cotilédones no eixo (e); plúmula (f); região proximal do cotilédone (g); região distal do cotilédone (h).

Figure 1. Longitudinal section of embryo of brazilwood. a-d. hipocotyl-radicle axis: radicle (a); protoderm (b); fundamental meristem (c) and procambium (d); cotyledon insertion region (e); plumule (f); nearest region (g); distal region (h). 
de água destilada no fundo, evitando-se o contato direto da água com as sementes (Marcos Filho 1994). As sementes foram incubadas por períodos de 4, 8, 12, 16, 24, 48 e 72 horas. Ao final de cada período foram avaliados o teor de água, o potencial hídrico, a germinação e o vigor, conforme descrito anteriormente.

Concentração do sal de tetrazólio e período de exposição dos embriões de lotes de diferentes qualidades - Duas concentrações do sal cloreto 2,3,5 trifenil tetrazólio ( $0,050 \%$ e $0,075 \%$ ) e dois períodos de incubação (2 e 4 horas) foram aplicados a sementes de Mogi Guaçu, com três qualidades fisiológicas distintas, obtidas pela exposição daquele lote a dois períodos de envelhecimento acelerado (12 e 24 horas), baseando-se nos resultados do experimento anterior. Ao final da incubação, seguiram-se os mesmos procedimentos descritos acima.

Categorização das sementes segundo o grau de deterioração - Após a definição da melhor combinação entre concentração do sal, tempo de exposição e temperatura e, ainda, após avaliações realizadas nas sementes com diferentes níveis de deterioração, estabelecidas pelo envelhecimento acelerado, foram definidas classes de viabilidade e deterioração, segundo a cor de cada tecido da semente incubada no teste de tetrazólio. Para tanto, cada semente foi classificada como germinável (semente capaz de produzir plântula normal), viável (semente sem capacidade de produzir plântula normal, mas podendo emitir raiz primária), não germináveis (semente sem capacidade de emitir raiz, mas com tecidos vivos) ou morta (semente sem tecidos vivos).

As classes previstas foram: Classe 1 (germinável) - embriões com coloração rósea suave uniforme e tecidos com aspectos normais e túrgidos; Classe 2 (germinável) - pequenas regiões de coloração vermelho intenso na extremidade dos cotilédones, porém eixo embrionário mantendo coloração rósea suave; Classe 3 (viável) - eixo embrionário com regiões de cor vermelha intensa, porém em extensão menor que a metade de sua espessura e sem incluir a radícula; cotilédones podendo apresentar coloração vermelho intenso na extremidade e na região proximal; Classe 4 (viável) - eixo embrionário com amplas regiões de coloração vermelho intenso, inclusive a radícula; cotilédones com regiões de coloração vermelha intensa ou pequenas pontuações descoloridas, afetando parte da região proximal, exceto a região de inserção dos cotilédones no eixo; Classe 5 (não germináveis) - embriões com coloração vermelha intensa em sua totalidade; Classe 6 (não germináveis) - eixo embrionário com regiões descoloridas afetando, inclusive, o procâmbio; cotilédones com coloração vermelho intenso, mas com regiões descoloridas, inclusive afetando a região proximal; Classe 7 (não germináveis) - embriões descoloridos em mais de 75\% de sua superfície; Classe 8 (morta) - embriões completamente descoloridos.

Delineamento experimental e análises estatísticas - O delineamento experimental para todos os experimentos foi inteiramente casualizado, com 4 repetições. Os valores foram submetidos à análise de variância (teste F), ao nível de 5\% de probabilidade. Para a obtenção da curva de embebição das sementes, aos valores obtidos procurou-se ajustar regressões polinomiais até terceiro grau. Nos demais experimentos, as médias foram comparadas entre si pelo teste de Tukey, também ao nível de 5\%. Quando necessário para correção da normalidade e da heterogeneidade, os valores foram transformados para arc sen (\%) $)^{0,5}$ (Santana \& Ranal 2004).

\section{Resultados e discussão}

Obtenção da curva de hidratação das sementes - Os resultados obtidos para embebição de sementes de paubrasil (figura 2A) demonstraram que o final da fase I (Bewley \& Black 1994) ocorreu por volta de 120 minutos após o início da embebição. Além disso, permitiu verificar que o processo de embebição de sementes de pau-brasil é bastante rápido, duplicando o teor inicial de água (7\%) já no primeiro minuto de embebição, triplicando com mais dois minutos e chegando a quintuplicar nos primeiros 10 minutos, quando atingiu cerca de $30 \%$ de água (figura 2B). Essa velocidade de embebição era esperada uma vez que a fase I da embebição é dirigida pelo gradiente de potencial hídrico entre a semente e o meio (Castro et al. 2004) que, no presente trabalho, foi próximo a zero (papel de germinação saturado com água pura). As sementes de pau-brasil apresentaram, inicialmente, -195,5 MPa, passando a -25,0 MPa após 5 minutos e a -5,1 MPa após 10 minutos de embebição (figura 2C).

A realização da curva de embebição nas sementes de pau-brasil (figura 2) permitiu estabelecer o período mínimo de pré-condicionamento (2 horas), ou seja, o necessário para que as sementes atingissem ao menos o início da fase II, evitando-se que atingissem a fase III (6 horas). O pré-condicionamento visa a, apenas, facilitar a penetração da solução de tetrazólio e o desenvolvimento de uma coloração mais clara e evidente, amolecer os tecidos, facilitando a remoção dos tegumentos e o corte longitudinal dos embriões (Delouche et al. 1976) e ativar os sistemas enzimáticos respiratórios (Marcos Filho 2005). Não necessita, portanto, que se inicie a divisão celular, característica da fase III.

Concentração do sal de tetrazólio e período de exposição de sementes inteiras - Os resultados iniciais obtidos para o teste de tetrazólio em sementes inteiras de pau-brasil (tabela 1) demonstraram a necessidade de utilização de solução com baixas concentrações do sal. Comparando-se com os valores obtidos no teste de germinação da amostra de sementes analisada, ou seja, 32\% de germinação e 15\% de desenvolvimento de 

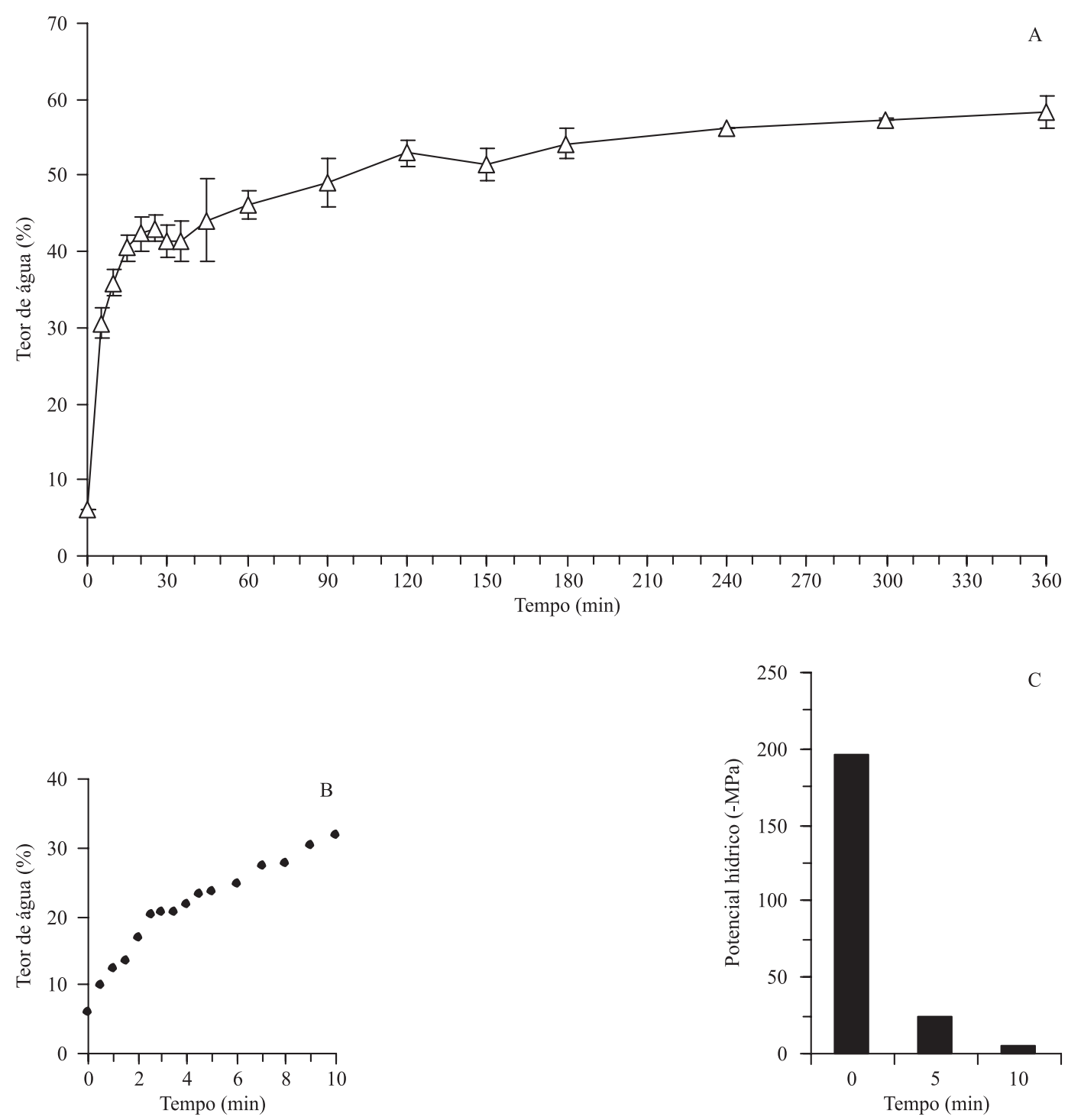

Figura 2. Embebição de sementes de pau-brasil até 360 minutos (A), nos primeiros 10 minutos (B) e correspondentes modificações no potencial hídrico do embrião (C).

Figure 2. Seed imbibition of brazilwood from 0 to 360 minutes (A), during the first 10 minutes (B), and correspondent water potential changes (C).

plântulas normais, a combinação tempo × concentração da solução que mais se aproximou dos valores reais foi $0,250 \%$ por 2 horas (tabela 1 ), embora em todos os tratamentos houve dificuldade de análise das sementes pela excessiva coloração desenvolvida.

A combinação da concentração de $0,250 \%$ pelo período de 2 horas de incubação mostrou-se eficiente para a estimativa da germinação (tabela 2), uma vez que não houve interação significativa entre o nível de deterioração das sementes e o mecanismo de análise da germinação (teste de germinação ou teste de tetrazólio). Contudo, o mesmo não se pode afirmar para análises mais aprofundadas da real qualidade das sementes, pois houve interação significativa entre aqueles fatores para as variáveis plântulas normais e sementes mortas (tabela 2). A excessiva coloração desenvolvida a 0,250\% por 2 horas prejudicou, sobretudo, a visualização de pequenas áreas com tecido em processo de deterioração, o qual seria caracterizado por coloração mais intensa que o tecido sadio (França Neto et al. 1998).

Concentração do sal de tetrazólio e período de exposição de embriões sem tegumento - em amostras de sementes incubadas sem o tegumento notou-se melhor 
uniformidade no desenvolvimento de coloração e maior facilidade na análise visual.

Outro aspecto importante observado nos primeiros experimentos é que as sementes apresentavam trincas (figura 3B), o que provavelmente facilitava a difusão da solução de tetrazólio para o interior das sementes. Nos experimentos posteriores, com sementes intactas (figura 3A), notou-se dificuldade naquela difusão. Assim, nos experimentos que se seguiram optou-se por incubar embriões (figura 3C), removendo-se o tegumento das

Tabela 1. Germinação de sementes, desenvolvimento de plântulas normais e sementes não germináveis de paubrasil, de sementes com tegumento, analisadas pelo teste de tetrazólio, em função da variação na concentração do sal e no período de incubação. Médias seguidas pela mesma letra (minúsculas nas colunas, maiúsculas nas linhas) não diferem entre si pelo teste de Tukey, a 5\%.

Table 1. Seed germination, normal seedling development and non-germinated seeds of brazilwood analyzed by tetrazolium test at different concentration of the solution and different incubation period (seeds with tegument). Means followed by the same letter (small for columns, capital for lines) did not differ by Tukey at $5 \%$.

\begin{tabular}{|c|c|c|c|c|}
\hline \multirow{2}{*}{$\begin{array}{l}\text { Tempo de } \\
\text { incubação }\end{array}$} & \multicolumn{3}{|c|}{ Concentração da solução } & \multirow{2}{*}{ Médias } \\
\hline & $0,250 \%$ & $0,500 \%$ & $1,000 \%$ & \\
\hline & \multicolumn{3}{|c|}{ Germinação (\%) } & \\
\hline 2 horas & 30 & 60 & 75 & $55 \mathrm{a}$ \\
\hline 4 horas & 55 & 65 & 55 & 58 a \\
\hline 12 horas & 50 & 70 & 60 & 60 a \\
\hline 24 horas & 35 & 85 & 77 & 66 a \\
\hline Médias & $42 \mathrm{~B}$ & $70 \mathrm{~A}$ & $67 \mathrm{~A}$ & \\
\hline \multirow[t]{2}{*}{ Coef. var. } & \multicolumn{3}{|c|}{$21,65 \%$} & \\
\hline & \multicolumn{3}{|c|}{ Plântulas normais (\%) } & \\
\hline 2 horas & 15 & 30 & 50 & 32 a \\
\hline 4 horas & 40 & 45 & 25 & 37 a \\
\hline 12 horas & 20 & 35 & 40 & 32 a \\
\hline 24 horas & 5 & 10 & 5 & $7 \mathrm{~b}$ \\
\hline Médias & $20 \mathrm{~B}$ & $30 \mathrm{~A}$ & $30 \mathrm{~A}$ & \\
\hline \multirow[t]{2}{*}{ Coef. var. } & \multicolumn{3}{|c|}{$44,34 \%$} & \\
\hline & \multicolumn{3}{|c|}{ Sementes não germináveis (\%) } & \\
\hline 2 horas & 45 & 20 & 20 & 28 a \\
\hline 4 horas & 20 & 15 & 15 & 17 a \\
\hline 12 horas & 35 & 15 & 20 & 23 a \\
\hline 24 horas & 55 & 15 & 15 & $28 \mathrm{a}$ \\
\hline Médias & $39 \mathrm{~A}$ & $16 \mathrm{~A}$ & $18 \mathrm{~A}$ & \\
\hline Coef. var. & \multicolumn{3}{|c|}{$44,12 \%$} & \\
\hline
\end{tabular}

Tabela 2. Germinação de sementes, desenvolvimento de plântulas normais e sementes mortas de pau-brasil, de sementes com três níveis de deterioração, analisadas pelo teste de germinação e pelo teste de tetrazólio (sementes com tegumento). Médias seguidas pela mesma letra (minúsculas nas colunas, maiúsculas nas linhas) não diferem entre si pelo teste de Tukey, a $5 \%$.

Table 2. Seed germination, normal seedling development and dead seeds of brazilwood of three levels of deterioration, analyzed by both germination and tetrazolium tests (seeds with tegument). Means followed by the same letter (small for columns, capital for lines) did not differ by Tukey at 5\%.

\begin{tabular}{|c|c|c|c|}
\hline \multirow{2}{*}{$\begin{array}{l}\text { Nível de } \\
\text { deterioração }\end{array}$} & \multicolumn{2}{|c|}{ Tipo de teste } & \multirow{2}{*}{ Médias } \\
\hline & Germinação & Tetrazólio & \\
\hline & \multicolumn{2}{|c|}{ Germinação (\%) } & \\
\hline Leve & 68 & 50 & 59 a \\
\hline Intermediário & 18 & 12 & $15 \mathrm{~b}$ \\
\hline Severo & 0 & 0 & $0 \mathrm{c}$ \\
\hline Médias & $28 \mathrm{~A}$ & $20 \mathrm{~A}$ & \\
\hline \multirow[t]{2}{*}{ Coef. var. } & \multicolumn{2}{|c|}{$38,65 \%$} & \\
\hline & \multicolumn{2}{|c|}{ Plântulas normais (\%) } & \\
\hline Leve & 38 aA & $10 \mathrm{aB}$ & - \\
\hline Intermediário & $0 \mathrm{bA}$ & $0 \mathrm{aA}$ & - \\
\hline Severo & $0 \mathrm{bA}$ & $0 \mathrm{aA}$ & - \\
\hline \multirow[t]{2}{*}{ Coef. var. } & \multicolumn{2}{|c|}{$97,62 \%$} & \\
\hline & \multicolumn{2}{|c|}{ Sementes mortas (\%) } & \\
\hline Leve & 38 cA & $0 \mathrm{bB}$ & - \\
\hline Intermediário & 82 bA & $0 \mathrm{bB}$ & - \\
\hline Severo & $100 \mathrm{aA}$ & 100 aA & - \\
\hline Coef. var. & \multicolumn{2}{|r|}{$8,27 \%$} & \\
\hline
\end{tabular}

sementes. Os valores do teste de tetrazólio de embriões de pau-brasil sem a presença de tegumento estão apresentados na tabela 3.

As combinações 4, 6 e 8 horas nas concentrações $0,125 \%$ e $0,250 \%$ mostraram-se inadequadas para avaliação da qualidade das sementes uma vez que o teste de germinação apresentou apenas $48 \%$ de sementes inviáveis, contra os $85 \%$ obtidas pelo teste do tetrazólio (sementes não germináveis + mortas, tabela 3). Essas combinações desenvolveram nos embriões extensas manchas de coloração vermelho-intenso indicando excesso de tempo na incubação e forte concentração da solução de tetrazólio (figura 3E).

Considerando-se ser a mesma amostra, as variações obtidas na coloração dos embriões permitiram definir melhor a combinação tempo × concentração. O período de 

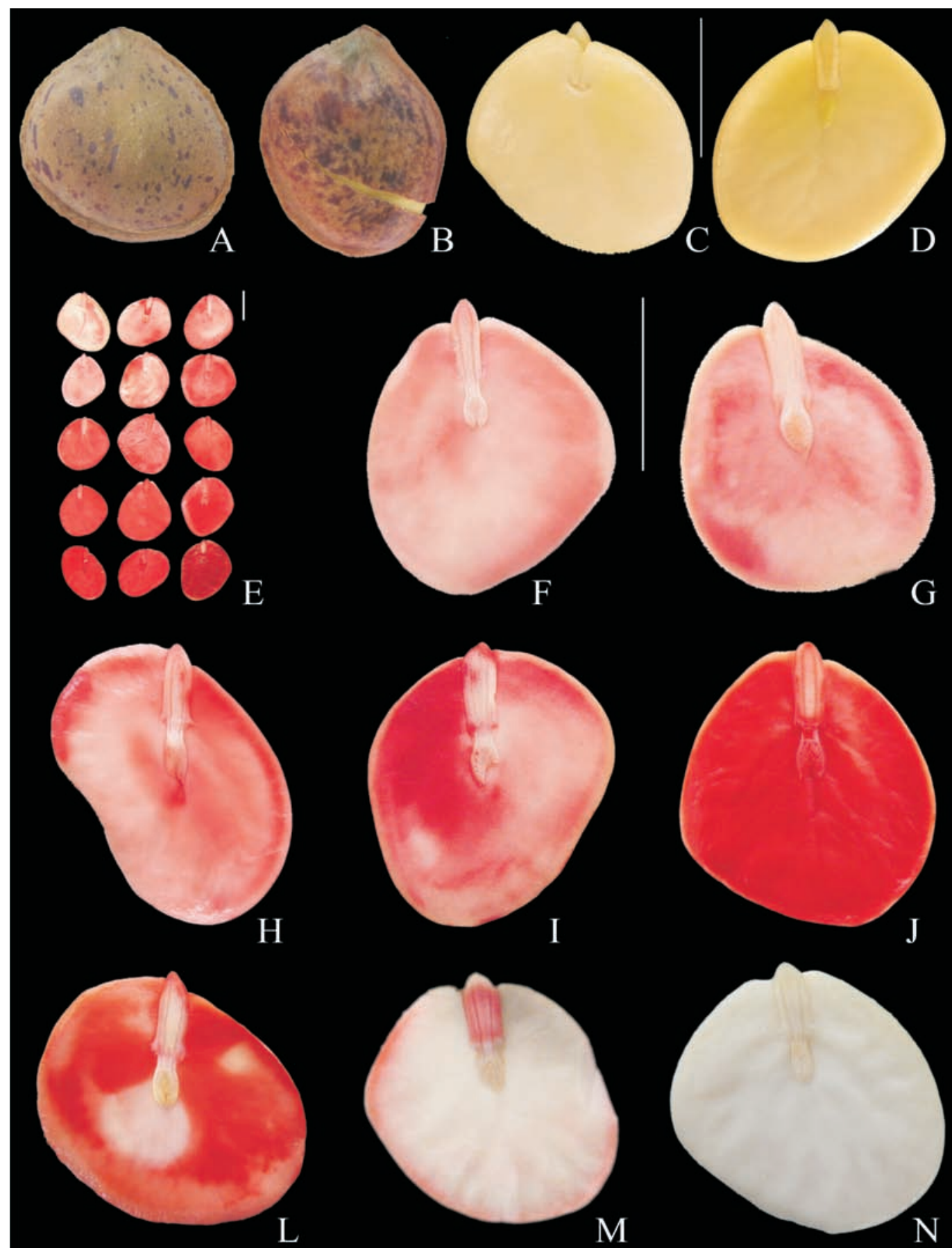

Figura 3. Sementes de pau-brasil submetidas ao teste de tetrazólio. A. Semente intacta. B. Semente com trinca no tegumento. C. Embrião. D. Embrião em secção longitudinal com remoção de um dos cotilédones. E. Embriões coloridos em solução de tetrazólio de diferentes concentrações, incubados por diferentes períodos (da esquerda para direita, 0,075\%, 0,125\% e 0,250\%; de cima para baixo, 1, 2, 4, 6 e 8 horas). F-N. Classes para avaliação de vigor e viabilidade das sementes pelo teste de tetrazólio. (F. Classe 1. G. Classe 2. H. Classe 3. I. Classe 4. J. Classe 5. L. Classe 6. M. Classe 7. N. Classe 8). De E a N: visão interna dos embriões dos quais foi retirado um dos cotilédones. Escala $=1 \mathrm{~cm}$.

Figure 3. Seeds of brazilwood in the tetrazolium test. A. Intact seed. B. Seed with cracked testa. C. Embryo. D. Longitudinal section of embryo. E. Embryos coloured by different tetrazolium solution concentrations and incubated for different periods (from left to right, $0.075 \%, 0.125 \%$ e $0.250 \%$; from top to bottom, 1, 2, 4, 6 and 8 hours). F-N. Groups of coloured embryos analyzed as for vigor and viability (F. Group 1. G. Group 2. H. Group 3. I. Group 4. J. Group 5. L. Group 6. M. Group 7. N. Group 8). From E to N. Internal image of embryos without one cotyledon. Scale $=1 \mathrm{~cm}$. 
Tabela 3. Germinação, desenvolvimento de plântulas normais e sementes não germináveis de pau-brasil, obtidos da análise de embriões no teste de tetrazólio, em função da variação na concentração do sal e no período de incubação dos embriões (sementes sem tegumento). Médias seguidas pela mesma letra (minúsculas nas colunas, maiúsculas nas linhas) não diferem entre si pelo teste de Tukey, a 5\%.

Table 3. Seed germination, normal seedling development and non-germinated seeds of brazilwood from tetrazolium test applied to embryos at different concentration of the solution and different incubation period (seeds without tegument). Means followed by the same letter (small for columns, capital for lines) did not differ by Tukey at 5\%.

\begin{tabular}{|c|c|c|c|}
\hline \multirow{2}{*}{$\begin{array}{l}\text { Tempo de } \\
\text { incubação }\end{array}$} & \multicolumn{3}{|c|}{ Concentração da solução } \\
\hline & $0,075 \%$ & $0,125 \%$ & $0,250 \%$ \\
\hline & \multicolumn{3}{|c|}{ Germinação (\%) } \\
\hline 1 hora & $17 \mathrm{bA}$ & 12 aA & 5 aA \\
\hline 2 horas & $40 \mathrm{aA}$ & $15 \mathrm{aB}$ & $3 \mathrm{aB}$ \\
\hline 4 horas & $25 \mathrm{abA}$ & $10 \mathrm{aAB}$ & $12 \mathrm{aB}$ \\
\hline 6 horas & 12 bA & 7 aA & $7 \mathrm{aA}$ \\
\hline 8 horas & $12 \mathrm{bA}$ & $5 \mathrm{aA}$ & $7 \mathrm{aA}$ \\
\hline \multirow[t]{2}{*}{ Coef. var. } & \multicolumn{3}{|c|}{$64,41 \%$} \\
\hline & \multicolumn{3}{|c|}{ Plântulas normais (\%) } \\
\hline 1 hora & $3 \mathrm{bA}$ & $5 \mathrm{aA}$ & $0 \mathrm{aA}$ \\
\hline 2 horas & $20 \mathrm{aA}$ & $0 \mathrm{aB}$ & $0 \mathrm{aB}$ \\
\hline 4 horas & $7 \mathrm{bA}$ & $0 \mathrm{aA}$ & $0 \mathrm{aA}$ \\
\hline 6 horas & $3 \mathrm{bA}$ & $0 \mathrm{aA}$ & $0 \mathrm{aA}$ \\
\hline 8 horas & $5 \mathrm{bA}$ & 0 aA & $0 \mathrm{aA}$ \\
\hline \multirow[t]{2}{*}{ Coef. var. } & \multicolumn{3}{|c|}{$168,44 \%$} \\
\hline & \multicolumn{3}{|c|}{ Sementes não germináveis (\%) } \\
\hline 1 hora & 80 aA & 85 aA & 95 aA \\
\hline 2 horas & $60 \mathrm{bB}$ & 85 aA & $97 \mathrm{aA}$ \\
\hline 4 horas & 72 abB & $90 \mathrm{aA}$ & $87 \mathrm{aAB}$ \\
\hline 6 horas & 87 aA & 92 aA & $92 \mathrm{aA}$ \\
\hline 8 horas & 87 aA & 95 aA & $92 \mathrm{aA}$ \\
\hline Coef. var. & & $10,32 \%$ & \\
\hline
\end{tabular}

8 horas, por exemplo, considerado excessivo, posicionou cerca de 50\% dos embriões na classe 5 (figura 3J), ou seja, embriões que desenvolveram coloração vermelho-intenso em sua totalidade. Por outro lado, o período de 1 hora de incubação no tetrazólio desenvolveu uma coloração inadequada (figura 3E), pois muitas regiões dos embriões estavam descoloridos ou com coloração amarela, o que os situaria nas classes 7 e 8 (figuras 3M, N).

Os períodos de 2 e 4 horas a $0,075 \%$ proporcionaram o desenvolvimento de coloração rósea suave em grandes extensões dos embriões (figura 3E) e, comparando-se com os valores do teste de teste de germinação, o período de 2 horas a $0,075 \%$ foi o que mais se aproximou dos valores reais.

Aremoção do tegumento após o pré-condicionamento mostrou-se adequada para o teste de tetrazólio. Amostras incubadas com tegumento até 8 horas não desenvolveram coloração adequada e uniforme e apenas as extremidades dos embriões se coloriram, permanecendo a parte central descolorida (dados não apresentados).

Em relação à temperatura, as inferiores a $35^{\circ} \mathrm{C}$ resultaram em coloração desuniforme, não favorecendo uma avaliação confiável, agrupando a maioria dos embriões nas classes 6 e 7 (figuras 3 L, M). A incubação a $35^{\circ} \mathrm{C}$, por sua vez, favoreceu as reações das enzimas desidrogenases em sementes de C. echinata com o sal de tetrazólio nos embriões, que desenvolveram coloração mais homogênea, permitindo diferenciar com clareza as tonalidades de vermelho e agrupar com maior confiabilidade os embriões nas classes previstas.

Obtenção de sementes com diferentes graus de deterioração - A germinação e o vigor das sementes de pau-brasil diminuíram progressivamente desde o início do período de envelhecimento acelerado até o último período (72 horas), ora reduzindo apenas a velocidade de germinação, ora a própria protrusão da raiz primária. Essas reduções foram acompanhadas de elevação no teor de água e no potencial hídrico (tabela 4).

Assim, nos dois primeiros períodos de envelhecimento (4 e 8 horas, tabela 4) não houve queda no vigor ou mesmo na porcentagem de germinação, mas já a partir de 12 horas de envelhecimento notou-se queda no IVG (tabela 4), indicando ser esse um período adequado para compor amostra com sementes em início de deterioração. De 12 a 16 horas não se verificaram alterações significativas mas, a partir de 24 horas, os valores de desenvolvimento de plântulas normais diferiram da testemunha (inicial). Portanto, este período foi considerado também importante para a composição das amostras a serem avaliadas no teste de tetrazólio.

A partir de 48 horas, as sementes começaram a apresentar queda na porcentagem de germinação, indicando que as sementes passaram a um estágio avançado de deterioração, não sendo mais interessante para inclusão no teste de tetrazólio. Conforme descrito por Popinigis (1977), a perda da capacidade da germinativa é a ultima etapa do processo de deterioração, ocorrendo antes das transformações degenerativas como alterações bioquímicas, físicas e citológicas. 
Tabela 4. Teor de água (base úmida), potencial hídrico, germinação, desenvolvimento de plântulas normais e índice de velocidade de germinação (IVG) de sementes de pau-brasil após diferentes períodos de exposição ao envelhecimento acelerado (EA) a $42{ }^{\circ} \mathrm{C}$ e $100 \%$ de umidade relativa. Médias seguidas pela mesma letra não diferem entre si pelo teste de Tukey, a 5\%.

Table 4. Seed water content (wet basis) and potential, seed germination, normal seedling development and speed of seed germination (IVG) of brazilwood after different accelerated aging periods (EA) at $42{ }^{\circ} \mathrm{C}, 100 \%$ relative humidity. Means followed by the same letter did not differ by Tukey at $5 \%$.

\begin{tabular}{lccccc}
\hline $\begin{array}{c}\text { Tempo de } \\
\text { exposição ao EA }\end{array}$ & $\begin{array}{c}\text { Teor de } \\
\text { água (\%) }\end{array}$ & $\begin{array}{c}\text { Potencial } \\
\text { hídrico (MPa) }\end{array}$ & $\begin{array}{c}\text { Germinação } \\
(\%)\end{array}$ & $\begin{array}{c}\text { Plântulas } \\
\text { normais (\%) }\end{array}$ & IVG \\
\hline 00 horas (inicial) & 13,8 & $-52,0$ & $95 \mathrm{a}$ & $82 \mathrm{a}$ & $8,0 \mathrm{a}$ \\
04 horas & 17,7 & $-25,4$ & $88 \mathrm{a}$ & $80 \mathrm{a}$ & $7,2 \mathrm{ab}$ \\
08 horas & 22,1 & $-16,9$ & $92 \mathrm{a}$ & $72 \mathrm{ab}$ & $7,1 \mathrm{ab}$ \\
12 horas & 29,3 & $-9,8$ & $85 \mathrm{ab}$ & $68 \mathrm{ab}$ & $5,8 \mathrm{bc}$ \\
16 horas & 32,3 & $-7,3$ & $75 \mathrm{abc}$ & $60 \mathrm{abc}$ & $4,8 \mathrm{~cd}$ \\
24 horas & 38,0 & $-5,4$ & $70 \mathrm{abc}$ & $45 \mathrm{bcd}$ & $3,8 \mathrm{cde}$ \\
$\mathbf{4}$ horas & 38,6 & $-5,1$ & $55 \mathrm{bc}$ & $35 \mathrm{~cd}$ & $3,2 \mathrm{de}$ \\
72 horas & 41,4 & $-4,4$ & $48 \mathrm{c}$ & $30 \mathrm{~d}$ & $2,4 \mathrm{e}$ \\
\hline
\end{tabular}

O teor de água e o potencial hídrico durante o envelhecimento (tabela 4) confirmaram a grande capacidade dessas sementes em embeber rapidamente, conforme descrito anteriormente. Além disso, é importante ressaltar que a elevação do teor de água de $13,8 \%$ para $29,3 \%$ (12 horas) e $38,0 \%$ (24 horas) modifica o estado energético da água nas sementes, caracterizando a água tipo 3 (Vertucci \& Farrant 1995), com potencial hídrico entre -4 a $-11 \mathrm{MPa}$ (tabela 4). Essa modificação é importante por indicar respiração intensificada, mas os sistemas de reparos ainda não são ativados e a deterioração é acelerada (Marcos Filho 2005).

Concentração do sal e período de exposição em lotes de diferentes qualidades - a análise de variância não apontou interação entre os três fatores (nível de deterioração, concentração da solução e tempo de incubação), mas foram significativas as interações nível de deterioração $\times$ concentração e nível de deterioração $\times$ tempo de incubação para germinação e para sementes não germináveis (tabela 5).

Verificou-se que o período de 2 horas nas concentrações de $0,050 \%$ e a $0,075 \%$ permitiu o desenvolvimento de uma coloração adequada que facilitasse a avaliação da germinação e do vigor permitindo diferenciar os grupos de sementes de paubrasil. O período de 4 horas, independentemente da concentração, desenvolveu nos embriões coloração em tonalidades mais intensas de vermelho, não favorecendo a identificação dos embriões e induzindo a classificá-los como totalmente deteriorados.

Ambas as concentração foram eficientes para as análises, mas a concentração de 0,075\% desenvolveu, em alguns embriões, colorações mais acentuadas de vermelho, dificultando avaliação mais minuciosa. Como exemplo, a presença de estrias no eixo embrionário, típicas de sementes inviáveis, foram imperceptíveis quando utilizada essa concentração. A solução de tetrazólio a $0,05 \%$, por outro lado, desenvolveu uma tonalidade de coloração mais suave permitindo maior precisão na avaliação, possibilitando identificar a formação de pequenas lesões e estrias nos cotilédones e no eixo embrionário.

As sementes envelhecidas por 12 e 24 horas apresentaram manchas de grande extensão de coloração vermelho intenso, principalmente na região central dos cotilédones (região proximal). Esse comportamento provavelmente deve-se ao fato dessas regiões estarem mais expostas à condição de estresse. Como um dos primeiros sinais da deterioração é a perda da integridade das membranas, há um aumento na difusão da solução de tetrazólio nos tecidos (Delouche 2002, França Neto et al. 1998).

A análise de intensidade (rósea a vermelha) e distribuição de coloração ao longo das estruturas vitalícias (figura 1) para a germinação da semente permitiu confirmar as oito classes previstas inicialmente, tornando possível diagnosticar embriões viáveis, inviáveis (vivos mas não germináveis) e mortos. 
Tabela 5. Germinação, desenvolvimento de plântulas normais e sementes não germináveis de pau-brasil, de sementes com três níveis de deterioração (0, 12 e 24 h de envelhecimento acelerado), analisadas pelo teste de tetrazólio com duas concentrações do sal em embriões incubados por dois períodos. Médias seguidas pela mesma letra (minúsculas nas colunas, maiúsculas nas linhas) não diferem entre si pelo teste de Tukey, a 5\%.

Table 5. Seed germination, normal seedling development and non-germinated seeds of brazilwood submitted to three different levels of deterioration ( 0,12 and $24 \mathrm{~h}$ ). Results obtained by tetrazolium test at two different concentrations and two different incubation periods. Means followed by the same letter (small for columns, capital for lines) did not differ by Tukey at 5\%.

\begin{tabular}{|c|c|c|c|c|c|}
\hline \multirow{2}{*}{$\begin{array}{l}\text { Tempo de } \\
\text { envelhecimento }\end{array}$} & \multicolumn{2}{|c|}{ Concentração da solução } & \multicolumn{2}{|c|}{ Tempo de incubação } & \multirow{2}{*}{ Médias } \\
\hline & $0,050 \%$ & $0,075 \%$ & 2 horas & 4 horas & \\
\hline \multicolumn{6}{|c|}{ Germinação (\%) } \\
\hline 0 horas (inicial) & $30 \mathrm{aA}$ & $30 \mathrm{aA}$ & 39 aA & $21 \mathrm{aB}$ & - \\
\hline 12 horas & $21 \mathrm{aA}$ & $18 \mathrm{bA}$ & $20 \mathrm{bA}$ & $19 \mathrm{aA}$ & - \\
\hline 24 horas & $22 \mathrm{aA}$ & $10 \mathrm{bB}$ & $18 \mathrm{bA}$ & $15 \mathrm{aA}$ & - \\
\hline \multirow[t]{2}{*}{ Coef. var. } & & & $22,66 \%$ & & \\
\hline & \multicolumn{4}{|c|}{ Plântulas normais (\%) } & \\
\hline 0 horas (inicial) & 12 & 10 & 15 & 8 & $11,2 \mathrm{a}$ \\
\hline 12 horas & 6 & 4 & 5 & 5 & $5,0 \mathrm{~b}$ \\
\hline 24 horas & 5 & 1 & 4 & 2 & $3,1 \mathrm{~b}$ \\
\hline Médias & 7,9 A & $5,0 \mathrm{~A}$ & 7,9 A & $5,0 \mathrm{~A}$ & \\
\hline \multirow[t]{2}{*}{ Coef. var. } & \multicolumn{4}{|c|}{$87,56 \%$} & \\
\hline & \multicolumn{4}{|c|}{ Sementes não germináveis (\%) } & \\
\hline 0 horas (inicial) & $71 \mathrm{aA}$ & 68 bA & $60 \mathrm{bB}$ & 79 aA & - \\
\hline 12 horas & 79 aA & 85 aA & $82 \mathrm{aA}$ & $81 \mathrm{aA}$ & - \\
\hline 24 horas & $78 \mathrm{aB}$ & $90 \mathrm{aA}$ & $82 \mathrm{aA}$ & 85 aA & - \\
\hline Coef. var. & & & $9,98 \%$ & & \\
\hline
\end{tabular}

Portanto, pela metodologia de análise apresentada no presente trabalho, o teste de tetrazólio, desenvolvido para sementes de espécies cultivadas, pode também ser utilizado com segurança em sementes de espécies florestais nativas, como as sementes de pau-brasil, contribuindo para o gerenciamento eficiente de lotes de sementes, principalmente como ferramenta de preservação da biodiversidade vegetal.

Agradecimentos - Os autores agradecem aos funcionários da Reserva Ecológica e Estação Experimental de Mogi Guaçu, pelo auxílio na coleta das sementes e ao Instituto de Botânica, pela permissão para essas coletas; à Estação Ecológica de Tapacurá, pelas sementes fornecidas; à Coordenação de Aperfeiçoamento de Pessoal de Ensino Superior (Capes) pelas bolsas de mestrado concedidas a E.V. Lamarca e a S.N.M. Leduc; ao Conselho Nacional do Desenvolvimento Científico e Tecnológico (CNPq), pela bolsa de produtividade concedida a C.J. Barbedo e pelo auxílio financeiro ao projeto (Proc.481484/2007-8); à Fundação de Amparo à Pesquisa Científica do Estado de São Paulo (Fapesp), pelo auxílio financeiro ao projeto (Proc. 2005/04139-7); a Débora
Manzano Molizane, pela confecção das ilustrações e a Simone de Pádua Teixeira e Priscila Fratin Medina, pelo auxílio na identificação das diferentes estruturas nas sementes.

\section{Referências bibliográficas}

ANGYALOSSY, V., AMANO, E. \& ALVES, E.S. 2005. Madeiras utilizadas na fabricação de arcos de instrumentos de corda: aspectos anatômicos. Acta Botanica Brasilica 19:819-834.

BARBEDO, C.J., BILIA, D.A.C. \& FIGUEIREDORIBEIRO, R.C.L. 2002. Tolerância à dessecação e armazenamento de sementes de Caesalpinia echinata Lam. (pau-brasil), espécie da Mata Atlântica. Revista Brasileira de Botânica 25:431-439.

BEWLEY, J.D. \& BLACK, M. 1994. Seed physiology of development and germination. $2^{\text {nd }}$ ed. Plenum Press, London.

BILIA, D.A.C., MARCOS-FILHO, J. \& NOVEMBRE, A.D.L.C. 1998. Conservação da qualidade fisiológica de sementes de Inga uruguensis Hook. \& Arn. Revista Brasileira de Sementes 20:48-54. 
BORGES, I.F., DEL GIUDICE NETO, J., BILIA, D.A.C., FIGUEIREDO-RIBEIRO, R.C.L. \& BARBEDO, C.J. 2005. Maturation of seeds of Caesalpinia echinata Lam. (brazilwood), an endangered leguminous tree from the Brazilian Atlantic Forest. Brazilian Archives of Biology and Technology 48:851-861.

BRASIL, Ministério da Agricultura e Reforma Agrária. SNDA/DNDF, 1992. Regras para análises de sementes. Brasília.

CASTRO, R.D., BRADFORD, K. \& HILHORST, H.W. 2004. Embebição e reativação do metabolismo. In Germinação do básico ao aplicado (A.G. Ferreira \& F. Borghetti, orgs.). Artmed, Porto Alegre. p.148162.

DELOUCHE, J.C. 2002. Germinação, deterioração e vigor da semente. Seed News 6:1-7.

DELOUCHE, J.C., BHERING, M.C. \& LIENHARD, M. 1976. O teste de tetrazólio para viabilidade da semente. Agiplan, Brasília.

FERREIRA, R.A., VIEIRA, M.G.G.C., VON PINHO, E.V.R. \& TONETTI, O.A.O. 2001. Morfologia da semente e de plântulas e avaliação da viabilidade da semente de sucupira-branca (Pterodon pubescens Benth.-Fabaceae) pelo teste de tetrazólio. Revista Brasileira de Sementes 23:108-115.

FERREIRA, R.A., OLIVEIRA, L.M., TONETTI, O.A.O. \& DAVIDE, A.C. 2007. Comparação da viabilidade de sementes de Schizolobium parahyba (Vell.) Blake - Leguminosae Caesalpinioideae, pelos testes de germinação e tetrazólio. Revista Brasileira de Sementes 29:73-79.

FOGAÇA, C.A. 2003. Padronização do teste de tetrazólio para avaliação da viabilidade de sementes de três espécies florestais. Dissertação de mestrado, Universidade Estadual Paulista, Jaboticabal.

FRANÇA NETO, J.B. 1994. O teste de tetrazólio em sementes de soja. In Testes de vigor em sementes. (R.D. Vieira \& N.M. Carvalho, eds.). Funep, Jaboticabal. p.87-102.

FRANÇA NETO, J.B., KRYZANOWSKI, F.C., COSTA, N.P. 1998. El test de tetrazolio en semillas de soja. EmbrapaCNPSo. documentos nำ 117, Londrina.

HELLMANN, M.E., MELLO, J.I.O., FIGUEIREDORIBEIRO, R.C.L. \& BARBEDO, C.J. 2006. Tolerância ao congelamento de sementes de pau-brasil (Caesalpinia echinata Lam.) influenciada pelo teor de água. Revista Brasileira de Botânica 29:91-99.
ISTA. International Seed Testing Association. 1985. International rules for seed testing. Seed Science and Technology 13:356-513.

MAGUIRE, J.D. 1962. Speed of germination-aid in selection and evaluation for seedling emergence and vigor. Crop Science 2:176-177.

MARCOS FILHO, J. 1994. Teste de envelhecimento acelerado. In Testes de vigor em sementes. (R.D. Vieira \& N.M. Carvalho, eds.). Funep, Jaboticabal, p.133149.

MARCOS FILHO, J. 2005. Fisiologia de sementes de plantas cultivadas. Fealq, Piracicaba.

MELLO, J.I.O. \& BARBEDO, C.J. 2007. Temperatura, luz e substrato para a germinação de sementes de pau-brasil Caesalpinia echinata Lam., LeguminosaeCaesalpiniodeae. Revista Árvore 31:645-655.

MCDONALD, M. 1999. Seed quality assessment. Seed Science Research 8:265-275.

MOORE, R.P. 1985. Handbook on tetrazolium testing. Ista, Zürich.

OLIVEIRA, L.M., CARVALHO, M.L.M. \& NERY, M.C. 2005. Teste de tetrazólio em sementes de Tabebuia serratifolia Vahl Nich. e T. impetiginosa (Martius ex A.P. de Candolle) Standley - Bignoniaceae. Revista Ciência Agronômica 36:169-174.

POPINIGIS, F. 1977. Fisiologia da semente. Ministério da Agricultura / Agiplan, Brasília.

ROCHA, Y.T. 2004. Ibirapitanga: história, distribuição geográfica e conservação do pau-brasil (Caesalpinia echinata Lam., Leguminosae) do descobrimento à atualidade. Tese de doutorado, Universidade de São Paulo, São Paulo.

ROCHA, Y.T. \& BARBEDO, A.S.C. 2008. Pau-brasil (Caesalpinia echinata Lam., Leguminosae) na arborização urbana de São Paulo (SP), Rio de Janeiro (RJ) e Recife (PE). Revista SBAU 3:58-77.

SANTANA, D.G. \& RANAL, M.A. 2004. Análise da germinação: um enfoque estatístico. Ed. Universidade de Brasília, Brasília.

VERTUCCI, C.W. \& FARRANT, J.M. 1995. Acquisition and loss of desiccation tolerance. In Seed development and germination (J. Kigel \& G. Galili, eds.). Marcel Dekker Inc., New York, p.237-271.

VILLELA, F.A. \& PERES, W.B. 2004. Coleta, beneficiamento e armazenamento. In Germinação do básico ao aplicado (A.G. Ferreira \& F. Borghetti, orgs.). Artmed, Porto Alegre, p.265-281. 